\title{
Integrative analysis of indirect calorimetry and metabolomics profiling reveals alterations in energy metabolism between fed and fasted pigs
}

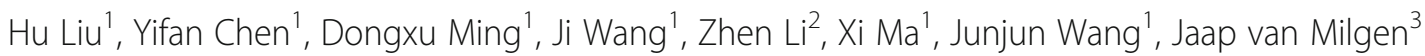
and Fenglai Wang ${ }^{1 *}$ (iD

\begin{abstract}
Background: Fasting is a simple metabolic strategy that is used to estimate the maintenance energy requirement where the energy supply for basic physiological functions is provided by the mobilization of body reserves. However, the underlying metabolic components of maintenance energy expenditure are not clear. This study investigated the differences in heat production $(\mathrm{HP})$, respiratory quotient $(\mathrm{RQ})$ and plasma metabolites in pigs in the fed and fasted state, using the techniques of indirect calorimetry and metabolomics.

Methods: Nine barrows (45.2 $\pm 1.7 \mathrm{~kg} \mathrm{BW}$ ) were fed corn-soybean based meal diets and were kept in metabolism crates for a period of $14 \mathrm{~d}$. After $7 \mathrm{~d}$ adaptation, pigs were transferred to respiratory chambers to determine HP and $\mathrm{RQ}$ based on indirect calorimetry. Pigs were fed the diet at 2,400 kJ ME/(kg BW $\left.{ }^{0.6} \cdot \mathrm{d}\right)$ during $\mathrm{d} 8$ to 12 . The last $2 \mathrm{~d}$ were divided into $24 \mathrm{~h}$ fasting and $48 \mathrm{~h}$ fasting treatment, respectively. Plasma samples of each pig were collected from the anterior vena cava during the last $3 \mathrm{~d}$ ( $1 \mathrm{~d}$ while pigs were fed and $2 \mathrm{~d}$ during which they were fasted). The metabolites of plasma were determined by high-resolution mass spectrometry using a metabolomics approach.

Results: Indirect calorimetry analysis revealed that HP and RQ were no significant difference between $24 \mathrm{~h}$ fasting and $48 \mathrm{~h}$ fasting, which were lower than those of fed state $(P<0.01)$. The nitrogen concentration of urine tended to decrease with fasting $(P=0.054)$. Metabolomics analysis between the fed and fasted state revealed differences in 15 compounds, most of which were not significantly different between $24 \mathrm{~h}$ fasting and $48 \mathrm{~h}$ fasting. Identified compounds were enriched in metabolic pathways related to linoleic acid metabolism, amino acid metabolism, sphingolipid metabolism, and pantothenate and CoA biosynthesis.

Conclusion: These results suggest that the decreases in $\mathrm{HP}$ and RQ of growing pigs under fasting conditions were associated with the alterations of linoleic acid metabolism and amino acid metabolism. The integrative analysis also revealed that growing pigs under a 24-h fasting were more appropriate than a 48-h fasting to investigate the metabolic components of maintenance energy expenditure.
\end{abstract}

Keywords: Fasting, Growing pig, Indirect calorimetry, Metabolomics, Plasma

\footnotetext{
* Correspondence: wangfl@cau.edu.cn

'State Key Laboratory of Animal Nutrition, China Agricultural University,

Beijing 100193, China

Full list of author information is available at the end of the article
}

(c) The Author(s). 2018 Open Access This article is distributed under the terms of the Creative Commons Attribution 4.0 International License (http://creativecommons.org/licenses/by/4.0/), which permits unrestricted use, distribution, and reproduction in any medium, provided you give appropriate credit to the original author(s) and the source, provide a link to the Creative Commons license, and indicate if changes were made. The Creative Commons Public Domain Dedication waiver (http://creativecommons.org/publicdomain/zero/1.0/) applies to the data made available in this article, unless otherwise stated. 


\section{Background}

Maintenance corresponds to the basal energy requirements for supporting body function, body temperature, and normal physical activity at a time when there is no net gain or loss of energy [1]. Though it is vital to the organism, little is known of the metabolic components of maintenance energy expenditure [2]. For nearly five decades, the fasting method has been used to estimate maintenance. During fasting, pigs mobilize body reserves resulting in a negative energy balance and, during a short duration of fasting, the fasting heat production may be related to the maintenance energy expenditure in the fed state $[3,4]$. Therefore, the fasting metabolism may, to some extent reflect, the metabolic components of maintenance in pigs [5]. A comparison between the fed and the fasted state will contribute to identify specific metabolic indicator of maintenance in pigs [6]. However, the duration of fasting has not been consistent in different studies [7, 8]. A series of studies have demonstrated that fasting duration plays a role in blood biochemistry and transcriptional regulation of metabolic genes. During the short-term fasting, plasma non-esterified fatty acids (NEFA) increased, while leptin and insulin concentrations were reduced $[9,10]$. In addition, pyruvate dehydrogenase in rat muscle and fatty acid synthase in rat adipose tissue decreased after $1 \mathrm{~d}$ of fasting [11]. During the longterm fasting, plasma glucose level was reduced by $48 \mathrm{~h}$ of fasting in fasted pigs and dairy cattle [10]. It was noted that the transcriptions of genes involved in the fatty acid oxidation began to decrease in 3-d fasted rat liver [11]. Thus, it is important to investigate the effect of fasting duration on plasma metabolic profiling to understand deeply the fasting metabolism.

Indirect calorimetry is a noninvasive method to study energy expenditure by respiratory gas exchange analysis [12]. However, changes in heat production (HP) and in the respiratory quotient (RQ) after fasting based on indirect calorimetry are a phenotypic reaction of an organism's metabolism, as it adapts to a different physiological and nutritional condition [13]. Fasting metabolism is associated with many metabolic changes that occur in the body when the animal has to rely on its body reserves to sustain maintenance $[14,15]$. Typically, the NEFA level in plasma increases $12 \mathrm{~h}$ after fasting in growing pigs [9]. Also, important increases in the ratio between NEFA and glycerol can be observed after prolonged fasting from $12 \mathrm{~h}$ to $36 \mathrm{~h}$ [6].

Plasma can be used as an accessible metabolic footprint that provides a picture of the metabolic events in the organisms and may reveal changes in metabolic pathways under various physiological or nutritional conditions [16, 17]. The metabolome is defined as the collection and global analysis of all small molecular metabolites generated in a cell, organ or organism [18].
Rubio-Aliaga et al. [6] used metabolomics of prolonged fasting in humans to reveal new catabolic markers. Thus, metabolomics is an ideal tool to explore the effect of fasting on plasma metabolites that result from synthetic and catabolic processes in growing pigs $[19,20]$.

However, what the association do the plasma metabolites of pigs have with alterations of components of energy expenditure or substrate oxidation pattern under fasting duration, to our knowledge, is not known clearly. We hypothesized that the changes in $\mathrm{HP}$ and $\mathrm{RQ}$ of fasted pigs were modulated by potential metabolic pathways related to energy metabolism. Therefore, the objective of present study was to investigate the effect of fasting treatment in growing pigs on the alterations in energy metabolism based on the integrative analysis of indirect calorimetry and metabolomics profiling.

\section{Methods}

\section{Animal, diets and experimental procedures}

The experimental protocol used in the present study was approved by the Institutional Animal Care and Use Committee at China Agricultural University. Nine growing barrows (Duroc $\times$ Landrace $\times$ Yorkshire), with an average initial BW of $45.2 \pm 1.7 \mathrm{~kg}$, were selected from the Fengning Swine Research Unit of China Agricultural University (Hebei, China). The experiment was conducted at the Laboratory of Animal Metabolism of China Agricultural University (Beijing, China). The basal diet (Table 1) was formulated based on corn and soybean meal.

The experiment was conducted in 3 consecutive periods (3 pigs per period) using the same facilities and similar experimental procedures because only 3 respiration chambers were available for the study. In each period, pigs were housed individually in metabolism cages and adapted to the cages and diet for $7 \mathrm{~d}$ prior to the start of the experimental period. Pigs were fed $2,400 \mathrm{~kJ} \mathrm{ME} /\left(\mathrm{kg} \mathrm{BW}{ }^{0.6} \cdot \mathrm{d}\right)$ daily during the adaptation period, which was close to the ad libitum feed intake. The experimental period was $7 \mathrm{~d}$, which was divided into three treatments. The first $5 \mathrm{~d}$ were feeding treatment. Pigs were also fed 2,400 kJ ME/(kg BW $\left.{ }^{0.6} \cdot \mathrm{d}\right)$ daily. The last $2 \mathrm{~d}$ were divided into $24 \mathrm{~h}$ fasting and $48 \mathrm{~h}$ fasting treatment, respectively. Pigs were fasted with ad libitum access to water via a low-pressure nipple drinker. During the adaptation and experimental period, all pigs were fed the same basal diet and had free access to water. During the experimental period, pigs were housed in metabolism cages that were placed inside open circuit respiratory chambers to determine HP and $\mathrm{RQ}$. The HP of fed state was calculated by averaged the daily HP of the 5-d feeing treatment. The 8-h HP from 22: $00 \mathrm{~h}(\mathrm{~d} \mathrm{13})$ to $06: 00 \mathrm{~h}(\mathrm{~d} \mathrm{14})$ and from 22:00 h (d 14) to 06: $00 \mathrm{~h}$ ( $\mathrm{d} 15)$ were calculated and then were extrapolated to a 24-h period, which were considered as the HP of $24 \mathrm{~h}$ 
Table 1 Composition and nutrient analysis of the basal diet, as-fed basis

\begin{tabular}{|c|c|}
\hline Items & Basal diet \\
\hline \multicolumn{2}{|l|}{ Ingredients, \% } \\
\hline Corn & 74.95 \\
\hline Soybean meal & 22.23 \\
\hline Dicalcium phosphate & 0.70 \\
\hline Limestone & 0.70 \\
\hline Salt & 0.35 \\
\hline Vitamin and mineral premix ${ }^{a}$ & 0.50 \\
\hline Lysine $\mathrm{HCl}$ & 0.39 \\
\hline Methionine & 0.05 \\
\hline Threonine & 0.11 \\
\hline Tryptophan & 0.02 \\
\hline \multicolumn{2}{|c|}{ Calculated chemical composition, $\%^{\mathrm{b}}$} \\
\hline SID Lysine & 0.98 \\
\hline SID Methionine & 0.28 \\
\hline SID Tryptophan & 0.17 \\
\hline SID Threonine & 0.59 \\
\hline \multicolumn{2}{|l|}{ Analyzed nutrient composition, \% } \\
\hline Dry matter & 88.60 \\
\hline Crude protein & 16.23 \\
\hline Ether extract & 2.66 \\
\hline Neutral detergent fibre & 12.80 \\
\hline Acid detergent fibre & 3.77 \\
\hline Calcium & 0.54 \\
\hline Total phosphorus & 0.55 \\
\hline Gross energy, MJ/kg & 16.45 \\
\hline
\end{tabular}

${ }^{a}$ Vitamin-mineral premix supplied the following nutrients per kilogram of diet: vitamin $\mathrm{A}, 5,512 \mathrm{IU}$; vitamin $\mathrm{D}_{3}, 2,200 \mathrm{IU}$; vitamin $\mathrm{E}, 30 \mathrm{IU}$; vitamin $\mathrm{K}_{3}, 2.2 \mathrm{mg}$; vitamin $B_{12}, 27.6 \mu$; riboflavin, $4 \mathrm{mg}$; pantothenic acid, $14 \mathrm{mg}$; niacin, $30 \mathrm{mg}$; choline chloride, $400 \mathrm{mg}$; folic acid, $0.7 \mathrm{mg}$; thiamine, $1.5 \mathrm{mg}$; pyridoxine, $3 \mathrm{mg}$; biotin, $44 \mu \mathrm{g} ; \mathrm{Mn}(\mathrm{MnO}), 40 \mathrm{mg} ; \mathrm{Fe}^{(}\left(\mathrm{FeSO}_{4} \cdot \mathrm{H} 2 \mathrm{O}\right), 75 \mathrm{mg} ; \mathrm{Zn}(\mathrm{ZnO})$, $75 \mathrm{mg} ; \mathrm{Cu}\left(\mathrm{CuSO}_{4} \cdot 5 \mathrm{H}_{2} \mathrm{O}\right), 100 \mathrm{mg}$; I (KI), $0.3 \mathrm{mg}$; $\mathrm{Se}\left(\mathrm{Na}_{2} \mathrm{SeO}_{3}\right), 0.3 \mathrm{mg}$

${ }^{\mathrm{b}} \mathrm{SID}$ values were referenced from NRC [77]

fasting treatment and $48 \mathrm{~h}$ fasting treatments, respectively. Pigs were fed twice daily an equal amount of meal, at 09:00 and 15:30 h. Feed refusals and spillage were recorded daily.

Pigs were weighed at the beginning of adaptation (d 0$)$, and on $\mathrm{d} 8,13,14$ and 15, which corresponded to the start or end of the different feeding regimens or fasting times. Temperature in the chambers was maintained at $22 \pm 1{ }^{\circ} \mathrm{C}$ during the feeding and fasting periods according to Zhang et al. [21].

\section{Blood collection and animal sampling}

The feeding, $24 \mathrm{~h}$ fasting and $48 \mathrm{~h}$ fasting treatments were terminated around $06: 00 \mathrm{~h}$ on $\mathrm{d} 13,14$ and 15 , respectively. Three blood samples were collected from the anterior vena cava of each pig at these three time points and represented the blood samples of feeding, $24 \mathrm{~h}$ fasting and $48 \mathrm{~h}$ fasting treatments. Samples were centrifuged (Heraeus, Hanau, Germany) at 3,000 $\times g$ for $10 \mathrm{~min}$ at $4{ }^{\circ} \mathrm{C}$, then the supernatants were transferred to storage tubes, frozen in liquid nitrogen, and stored at $-80{ }^{\circ} \mathrm{C}$ for subsequent metabolomics testing.

Urine was collected during the time that pigs were in the respiration chambers according to the methods described by Liu et al. [4]. In brief, urine was collected each morning for each pig in plastic buckets containing $50 \mathrm{~mL}$ of $6 \mathrm{~N} \mathrm{HCl}$ and sieved with cotton gauze, and filtered into a plastic bottle every day. The total quantity of collected urine was weighed and $5 \%$ of the daily urinary excretion was stored at $-20^{\circ} \mathrm{C}$. At the end of the experiment, urine collected during the first $5 \mathrm{~d}$ was thawed and mixed separately by individual animal and a sub-sample was saved for chemical analysis. Urine was collected separately during the $24 \mathrm{~h}$ fasting and $48 \mathrm{~h}$ fasting periods. The feed was ground through a $1-\mathrm{mm}$ screen and mixed thoroughly for chemical analysis.

\section{Chemical analysis and calculation}

All chemical analyses of ingredients and diet were conducted in duplicate. Dry matter (DM) was measured by drying the samples in a $135{ }^{\circ} \mathrm{C}$ drying oven for $2 \mathrm{~h}$ (method 930.15) [22]. The total crude protein $(\mathrm{N} \times 6.25)$ content of the samples was determined using the Kjeldahl method (method 984.13) [22]. Calcium was measured by titration with $0.1 \mathrm{~N} \mathrm{KMnO} 4$ (method 927.02) [22]. Total phosphorus was measured colorimetrically using a molybodovanadate reagent (method 965.17) [22]. Ether extract (EE) was determined using the Thiex method [23]. Neutral detergent fibre (NDF) and acid detergent fibre (ADF) were determined using filter bags and fibre analyser equipment (Fibre Analyzer; Ankom Technology, Macedon, NY, USA) following a modification of the procedure of van Soest et al. [24]. The gross energy (GE) in diets was determined using a Parr 6400 bomb calorimeter (Parr Instruments, Moline, IL). The nitrogen in urine were measured according to Liu et al. [4].

Heat production and RQ were calculated daily from $\mathrm{CO}_{2}$ and $\mathrm{CH}_{4}$ production, $\mathrm{O}_{2}$ consumption, and nitrogen excretion in the urine (UN) during the $5 \mathrm{~d}$ feeding period and the $2 \mathrm{~d}$ fasting period according to the following formulas by Brouwer et al. [25]:

$$
\begin{aligned}
& \mathrm{HP}(\mathrm{kJ})=16.1753 \times \mathrm{O}_{2}(\mathrm{~L})+5.0208 \times \mathrm{CO}_{2}(\mathrm{~L})-2.1673 \\
& \times \mathrm{CH}_{4}(\mathrm{~L})-5.9873 \times \mathrm{UN}(\mathrm{g}) \\
& \mathrm{RQ}=\mathrm{CO}_{2}(\mathrm{~L}) / \mathrm{O}_{2}(\mathrm{~L})
\end{aligned}
$$

\section{Sample preparation for metabolomics}

Six plasma samples selected randomly from each treatment were extracted using $800 \mu \mathrm{L}$ ice-cold extraction mix 
(acetonitrile:methanol, 1:1, v:v) at a 1:4 sample:extract solution ratio. After vortexing for $5 \mathrm{~min}$, the samples were centrifuged (Eppendorf, Germany) at $15,000 \times g$ for $10 \mathrm{~min}$ at $4{ }^{\circ} \mathrm{C}$ for deproteinization. The supernatant fractions were then collected and evaporated to dryness using a vacuum concentrator (Concentrator plus, Eppendorf). The resulting dry residues were re-suspended in $200 \mu \mathrm{L}$ of methanol: water (4:1), vortexed and centrifuged again at $15,000 \times g$ for $10 \mathrm{~min}$ at $4{ }^{\circ} \mathrm{C}$. Lastly, the supernatant fractions were filtered through a $0.1-\mu \mathrm{m}$ membrane and transferred to sampler vials to be analyzed on a UPLC-MS system.

\section{UPLC-MS analysis}

Plasma samples were analyzed with an UPLC-HRMS system (UPLC, ACQUITYUPLC H-Class Bio, Waters; MS, Q-Exactive, Termo Scientifc) equipped with a heated electrospray ionization (HESI) source. The UPLC separation was operated on a BEH C18 column $(2.1 \mathrm{~mm} \times 100 \mathrm{~mm}$, $1.7 \mu \mathrm{m}$, Waters). The HPLC grade solvents and additives from Fisher Scientifc (ThermoFisher Scientific, NJ, USA) were used. Mobile phase was comprised of $0.1 \%$ formic acid water solution (A) and $0.1 \%$ formic acid ACN solution (B). The gradient program was as follows: 95\% A at $0 \mathrm{~min}$ to $70 \% \mathrm{~A}$ at $5 \mathrm{~min}, 5 \% \mathrm{~A}$ at $10 \mathrm{~min}$ and held for $3 \mathrm{~min}$, then returned to initial condition. The flow rate was $0.3 \mathrm{~mL} / \mathrm{min}$. A sample of pooled plasma was reinjected after each six samples for quality control. The column temperature was set at $35{ }^{\circ} \mathrm{C}$ and the injection volume was $5 \mu \mathrm{L}$.

The MS analysis was performed in an electrospray ionization positive mode. Key parameters of the HESI source were as follows: spray voltage at $3 \mathrm{kV}$, capillary temperature at $320{ }^{\circ} \mathrm{C}$, sheath gas flow rate at 30 arb.units, aux gas flow rate at 10 arb. Units, sweep gas flow rate at 5 arb. Units, heater temperature at $350{ }^{\circ} \mathrm{C}$, and s-lens $\mathrm{RF}$ level at 55. Full scan data was acquired with a resolution of 70,000 in the mass range of $\mathrm{m} / \mathrm{z} 67.7-1,000$. For $\mathrm{MS} / \mathrm{MS}$ analysis, normalized collision was performed at an energy of $35 \mathrm{~V}$. In addition, an isolation window of $0.8 \mathrm{~m} / \mathrm{z}$ and a mass resolution of 35,000 were selected.

\section{Data mining and processing}

SIEVE 2.1 software (Thermo Scientific, NJ, USA) was used for metabolomics data processing. This software achieved background subtraction, peak alignment and component extraction of the raw data. Component extraction was performed according to the rules of retention time from 0.5 to $16 \mathrm{~min}$, intensity threshold at 500,000 , minimum scan at 9 and signal to noise ratio at 10. Principal components analysis (PCA) was carried out using SIMCA-P 13 software (Umetrics, Umea, Sweden) after data were scaled to Pareto variance. The compounds with $P<0.05$, fold change $>1.5$ and $C V<30 \%$ were picked by EXCEL for further identification.
Identification of differential compounds was performed in compound database of METLIN (https://metlin.scripps.edu/ landing_page.php?pgcontent=mainPage) and Human Metabolome Database (http://www.hmdb.ca) using accurate mass of molecular ions. The MS/MS spectra database was used to match fragment ion spectra of the candidate compounds. The MS/MS spectra were also compared with theoretical fragmentation patterns with mass accuracy at 5 ppm using Xcalibur ${ }^{\mathrm{TM}}$ (Thermo Scientific, NJ, USA).

\section{Statistical analysis}

Data generated in the present experiment were analyzed using the MIXED procedure of SAS (SAS Inst. Inc., Cary, NC) and repeated measurements were considered when analyzed the effects of fasting duration. The statistical model included the main effects of fasting duration. Pig was treated as the experimental unit. Treatment means were separated using the LSMEANS statement and Tukey's test was used for adjustment in multiple comparison. Results were considered significant at $P<0.05$ and considered as trends at $0.05<P<0.10$. Boxplot analysis of identified differential compounds were achieved using the $\mathrm{R}$ software package ( $\mathrm{R}$ Development Core Team, 2017,) version 3.4.1). The relative concentrations of differential compounds were imported into Metaboanalyst 3.0 (http://www.metaboanalyst.ca/faces/upload/ PathUploadView.xhtml) to generate the metabolome view map, which integrates enrichment analysis and pathway topology analysis. A metabolic pathway which pathway impact value is higher than 0.1 is characterized as the significantly relevant pathways.

\section{Results}

\section{Indirect calorimetry}

Compared to the fed state, the $\mathrm{O}_{2}$ consumption decreased at $24 \mathrm{~h}$ fasting and continued to decrease at $48 \mathrm{~h}$ fasting $(P<0.01)$ (Table 2). The $\mathrm{CO}_{2}$ and $\mathrm{CH}_{4}$ production of fasted pigs were significant lower than those of fed pigs, while those values were not significantly different between $24 \mathrm{~h}$ and $48 \mathrm{~h}$ fasting $(P<0.01)$. For HP and RQ, a significant decrease was observed after fasting treatment, but there were not significantly different between $24 \mathrm{~h}$ and $48 \mathrm{~h}$ fasting $(P<0.01)$. In addition, the UN production tended to decrease with fasting $(P=0.054)$.

\section{Plasma metabolic profiling based on UPLC-HRMS}

Principal components analysis was performed to reveal intrinsic differences within the signals (Fig. 1). The PCA score plot for plasma of pigs in the fed state, and after $24 \mathrm{~h}$ and $48 \mathrm{~h}$ of fasting showed clear clustering. PC 1 and PC 2 explained $67 \%$ of the total variances within the data. PC1 that described $52 \%$ of the variance between the fed and fasted state indicated that there were major differences in the metabolome between these two states, 
Table 2 The effect of fasting treatment on heat production, respiratory quotient and urine nitrogen in growing pigs

\begin{tabular}{|c|c|c|c|c|c|}
\hline \multirow[t]{2}{*}{ Items } & \multirow{2}{*}{$\begin{array}{l}\text { 2400, } \\
\mathrm{kJ} /\left(\mathrm{kg} \mathrm{BW}^{0.6} \cdot \mathrm{d}\right)\end{array}$} & \multicolumn{2}{|c|}{ Fasting } & \multirow[t]{2}{*}{ SEM } & \multirow[t]{2}{*}{$P$-value } \\
\hline & & $24 \mathrm{~h}$ & $48 \mathrm{~h}$ & & \\
\hline$n$ & 9 & 9 & 9 & & \\
\hline Body weight, kg & 47.6 & 48.4 & 46.1 & 1.9 & 0.68 \\
\hline $\begin{array}{l}\text { Oxygen consumption, } \\
\text { L/d }\end{array}$ & $569^{a}$ & $417^{\mathrm{b}}$ & $361^{c}$ & 19 & $<0.01$ \\
\hline $\begin{array}{l}\text { Carbon dioxide } \\
\text { production, L/d }\end{array}$ & $613^{\mathrm{a}}$ & $349^{b}$ & $294^{b}$ & 36 & $<0.01$ \\
\hline $\begin{array}{l}\text { Methane production, } \\
\text { L/d }\end{array}$ & $4.5^{\mathrm{a}}$ & $2.6^{\mathrm{b}}$ & $1.5^{\mathrm{b}}$ & 0.4 & $<0.01$ \\
\hline $\begin{array}{l}\text { Heat production, } \\
\mathrm{kJ} /\left(\mathrm{kg} \mathrm{BW} W^{0.6} \cdot \mathrm{d}\right)\end{array}$ & $1206^{a}$ & $828^{b}$ & $733^{b}$ & 36 & $<0.01$ \\
\hline Respiratory quotient & $1.07^{\mathrm{a}}$ & $0.84^{\mathrm{b}}$ & $0.81^{b}$ & 0.01 & $<0.01$ \\
\hline Urine nitrogen, $\mathrm{g} / \mathrm{d}$ & 9.52 & 6.83 & 6.45 & 0.92 & 0.054 \\
\hline
\end{tabular}

${ }^{\mathrm{abc}}$ Means in the same row with differing superscripts differ $(P<0.05)$

more than between $24 \mathrm{~h}$ and $48 \mathrm{~h}$ of fasting. The fasted samples differed along PC2 in the PCA score plots. After prolonged fasting, samples moved from the second quadrant to the third quadrant on the score plot, indicating that prolonged fasting alters the composition of the plasma metabolome.

Based on the accurate mass measurement of molecular ions and fragment ions with high resolution, 15 compounds were identified (Table 3). These metabolites belong to different metabolic classes: fatty acid, phospholipid, amino acids, and choline. Fold change was calculated by dividing the mean of normalized intensity of each plasma metabolite in the former by the mean of normalized intensity of each plasma in the latter. A fold change $>1$ indicates that the metabolite was down-regulated, whereas a fold change $<1$ indicates the metabolite was up-regulated. To illustrate the direction of changes at different time points, data were visualized in the form of box-plots.

Compared to the fed state, plasma 12,13-dihydroxyoctadecenoic acid (12,13-DHOME) and sphinganine levels significantly increased after fasting, slightly at $48 \mathrm{~h}$ of fasting and moderately at of $24 \mathrm{~h}$ fasting (Fig. 2). In accordance with the feeding stage, linoleic acid, stearidonic acid, oleic acid, palmitoleic acid, and tyrosine levels were low before fasting but increased and showed much larger variability after $24 \mathrm{~h}$ or $48 \mathrm{~h}$ of fasting. Also, pantothenic acid, lysophosphatidylcholine 18:0 (LysoPC (18:0)) and 5-aminopentanoic acid levels were higher at $48 \mathrm{~h}$ of fasting compared to those at $24 \mathrm{~h}$ of fasting. Not all metabolites were up-regulated during fasting. Levels of glycerophosphocholine (GPC), ornithine, and glutamine were significantly higher in the fed state compared to those at $24 \mathrm{~h}$ or $48 \mathrm{~h}$ of fasting. Plasma aminoadipic acid and betaine levels were similar in the fed state and at $48 \mathrm{~h}$ of fasting, but were lower at $24 \mathrm{~h}$ of fasting showed.

Pathway enrichment and pathway topology analysis were performed using MetaboAnalyst 3.0, which based on high-quality KEGG metabolic pathways as the backend knowledgebase (Fig. 3). Based on the identified metabolites and changes in their concentrations, five metabolic pathway had a pathway impact value higher than 0.1 , which is the cutoff value for relevance. The five significantly relevant metabolic pathways that indicated the growing pigs' responses to fasting treatment included: linoleic acid metabolism, pantothenate and CoA

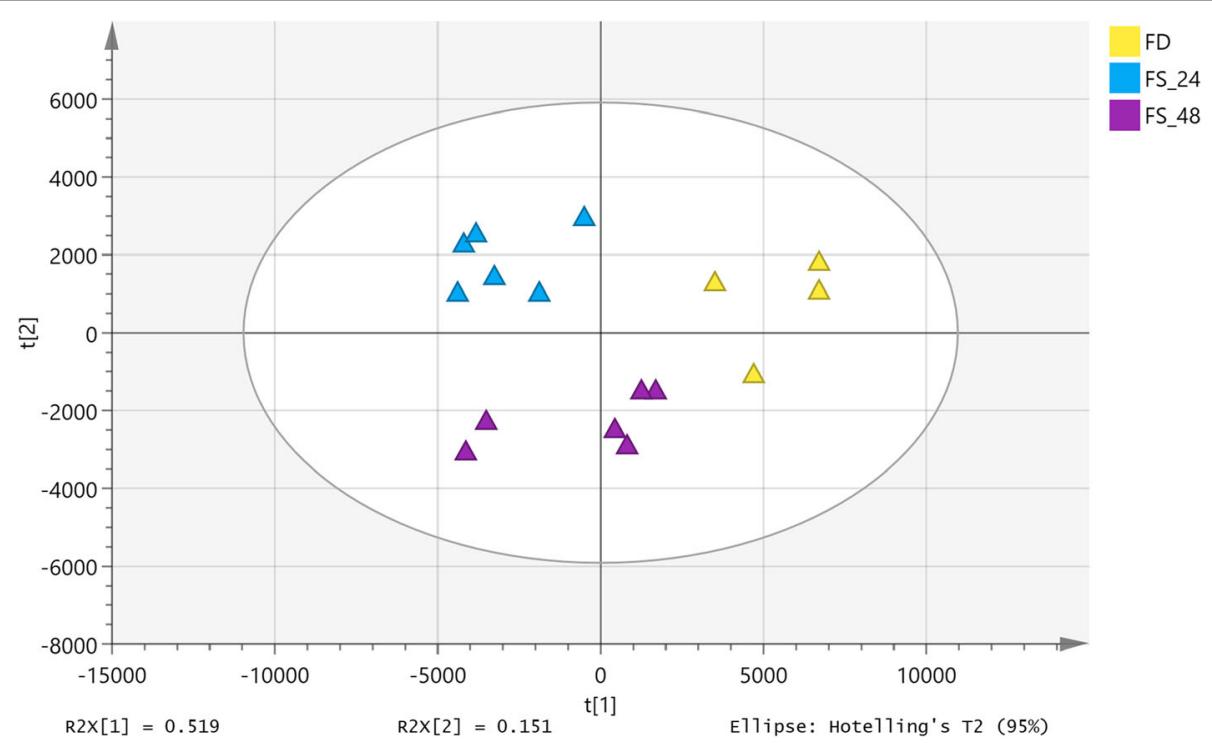

Fig. 1 PCA models demonstrating the separation of plasma samples of pigs under feeding, $24 \mathrm{~h}$ fasting and $48 \mathrm{~h}$ fasting. FD: Feeding; FS_24: $24 \mathrm{~h}$ fasting; FS_48: $48 \mathrm{~h}$ fasting. Each triangle represents an individual plasma sample 
Table 3 Metabolites with significant differences among feeding, $24 \mathrm{~h}$ of fasting and $48 \mathrm{~h}$ of fasting ${ }^{\mathrm{a}}$

\begin{tabular}{llllllll}
\hline No. & Name & $\mathrm{m} / \mathrm{z}$ & Formula & \multicolumn{2}{l}{ Fold change } & & Pathway analysis \\
\cline { 5 - 6 } & & & & FD/FS_24 & FD/FS_48 & FS_24/FS_48 & \\
\hline 1 & 12,13-DHOME & 297.2420 & $\mathrm{C}_{18} \mathrm{H}_{34} \mathrm{O}_{4}$ & 0.30 & 0.49 & 1.62 & Linoleic acid metabolism \\
3 & Linoleic acid & 263.2366 & $\mathrm{C}_{18} \mathrm{H}_{32} \mathrm{O}_{2}$ & 0.17 & 0.20 & 1.18 & Linoleic acid metabolism \\
4 & Stearidonic acid & 277.2157 & $\mathrm{C}_{18} \mathrm{H}_{28} \mathrm{O}_{2}$ & 0.11 & 0.11 & 1.02 & alpha-Linolenic acid metabolism \\
5 & Oleic acid & 300.2893 & $\mathrm{C}_{18} \mathrm{H}_{34} \mathrm{O}_{2}$ & 0.38 & 0.62 & 1.62 & Fatty acid metabolism \\
6 & Pantothenic acid & 220.1178 & $\mathrm{C}_{9} \mathrm{H}_{17} \mathrm{NO}_{5}$ & 1.22 & 0.72 & 0.59 & Pantothenate and CoA biosynthesis \\
7 & Glycerophosphocholine & 280.0917 & $\mathrm{C}_{8} \mathrm{H}_{20} \mathrm{NO}_{6} \mathrm{P}$ & 1.75 & 1.51 & 0.86 & Ether lipid metabolism \\
8 & LysoPC(O-18:0) & 510.3912 & $\mathrm{C}_{26} \mathrm{H}_{56} \mathrm{NO}_{6} \mathrm{P}$ & 1.02 & 0.34 & 0.33 & Ether lipid metabolism \\
9 & Sphinganine & 284.2942 & $\mathrm{C}_{18} \mathrm{H}_{39} \mathrm{NO}_{2}$ & 0.37 & 0.46 & 1.24 & Sphingolipid metabolism \\
10 & 5-Aminopentanoic acid & 118.0864 & $\mathrm{C}_{5} \mathrm{H}_{11} \mathrm{NO}_{2}$ & 1.30 & 0.84 & 0.65 & Lysine degradation \\
11 & Aminoadipic acid & 144.0654 & $\mathrm{C}_{6} \mathrm{H}_{11} \mathrm{NO}_{4}$ & 1.32 & 0.83 & 0.63 & Lysine degradation \\
12 & Betaine & 140.0681 & $\mathrm{C}_{5} \mathrm{H}_{11} \mathrm{NO}_{2}$ & 1.87 & 1.05 & 0.56 & Glycine, serine and threonine metabolism \\
13 & Ornithine & 133.0972 & $\mathrm{C}_{5} \mathrm{H}_{12} \mathrm{~N}_{2} \mathrm{O}_{2}$ & 2.00 & 1.64 & 0.82 & Arginine and proline metabolism \\
14 & L-Glutamine & 169.0582 & $\mathrm{C}_{5} \mathrm{H}_{10} \mathrm{~N}_{2} \mathrm{O}_{3}$ & 2.12 & 1.66 & 0.78 & Arginine and proline metabolism \\
15 & L-Tyrosine & 199.1076 & $\mathrm{C}_{9} \mathrm{H}_{11} \mathrm{NO}_{3}$ & 0.49 & 0.45 & 0.93 & Nitrogen metabolism \\
\hline
\end{tabular}

${ }^{\mathrm{a} F D}$ : Feeding; FS_24: $24 \mathrm{~h}$ fasting; FS_48: 48 h fasting; 12,13-DHOME: 12,13-dihydroxyoctadecenoic acid; LysoPC(18:0): lysophosphatidylcholine 18:0 ${ }^{b}$ Fold change was calculated by dividing the mean of normalized intensity of each plasma metabolite in the former by the mean of normalized intensity of each plasma in the latter. Fold change $>1$ indicates that the metabolite was down-regulated, whereas fold change $<1$ indicates the metabolite was up-regulated

biosynthesis, arginine and proline metabolism, alanine, aspartate, and glutamate metabolism, and sphingolipid metabolism.

\section{Discussion}

The term "indirect calorimetry" refers to the fact that heat production is determined by measuring $\mathrm{O}_{2}$ consumption, and $\mathrm{CO}_{2}$ and $\mathrm{CH}_{4}$ production, which are indicative for the oxidation of metabolites [26]. During fasting, these substrates are mainly glucose, lipids, and proteins mobilized from body reserves [27]. In the present study, heat production during fasting was significantly lower than that in the fed state, which indicates that the oxidation of substrate is down-regulated. Heat production at 24 and $48 \mathrm{~h}$ of fasting was 823 and $733 \mathrm{~kJ} /\left(\mathrm{kg} \mathrm{BW}^{0.6} \cdot \mathrm{d}\right)$, respectively. These values are within the range of fasting $\mathrm{HP}$ from 700 to $955 \mathrm{~kJ} /\left(\mathrm{kg} \mathrm{BW}{ }^{0.6} \cdot \mathrm{d}\right)$, which were determined in previous studies [28-31]. The variation might be partly explained by differences in the duration of fasting. The RQ is indicative for macronutrients that are being oxidized, as oxidation of glucose, lipids, and proteins yield different RQ values [32]. In the present study, the RQ at 24 and $48 \mathrm{~h}$ of fasting were 0.84 and 0.81 , respectively. A value of 0.7 indicates that lipids are being catabolized, 0.8 for proteins, and 1.0 for glucose [33]. The only occurrence of glucose oxidation in the body can be reflected in RQ values equal to 1.0 [34]. An RQ below 1.0 indicates that lipids and protein are being catabolized [35]. Therefore, the RQ of 0.84 and 0.81 indicates that mainly lipids and protein were oxidized during fasting [36, 37]. In addition, indirect calorimetry analysis revealed that the $\mathrm{HP}, \mathrm{RQ}$ and UN of growing pigs were no significant difference between $24 \mathrm{~h}$ fasting and $48 \mathrm{~h}$ fasting. These results can be explained that the energy metabolism of growing pigs under a 2-d fasting treatment was relatively stable, which were in agreement with the reports of Liu et al. [4] who also measured HP of fasted pigs using indirect calorimetry. Based on these results, a 24-h fasting treatment was more appropriate than a 48-h fasting treatment to determine the effect of fasting on the energy metabolism of growing pigs.

The body's principal lipid classes are mainly triglycerides, phospholipids, and steroids but triglycerides are quantitatively the most important lipids [38, 39]. Humans and animals will break down lipids to meet their energy requirements when the energy supply is restricted. This is a strategy to save glucose and protein that are crucial fuels for some important organs [40]. A series of studies have reported the effect of feed restriction and fasting on lipid metabolism [41-43]. Compared to biochemical traits in the blood of lipid metabolism, metabolomics provides new and a more in-depth information of the global metabolite profile of plasma [44, 45].

As mentioned above, five metabolites of unsaturated fatty acids (i.e., 12,13-DHOME, linoleic acid, stearidonic acid, oleic acid and palmitoleic acid were significantly up-regulated during fasting. Similar results have been reported in other studies in animals [13]. In the fed state, unsaturated fatty acids, saturated fatty acids, and glycerol are used to synthesize triglycerides [46]. During 


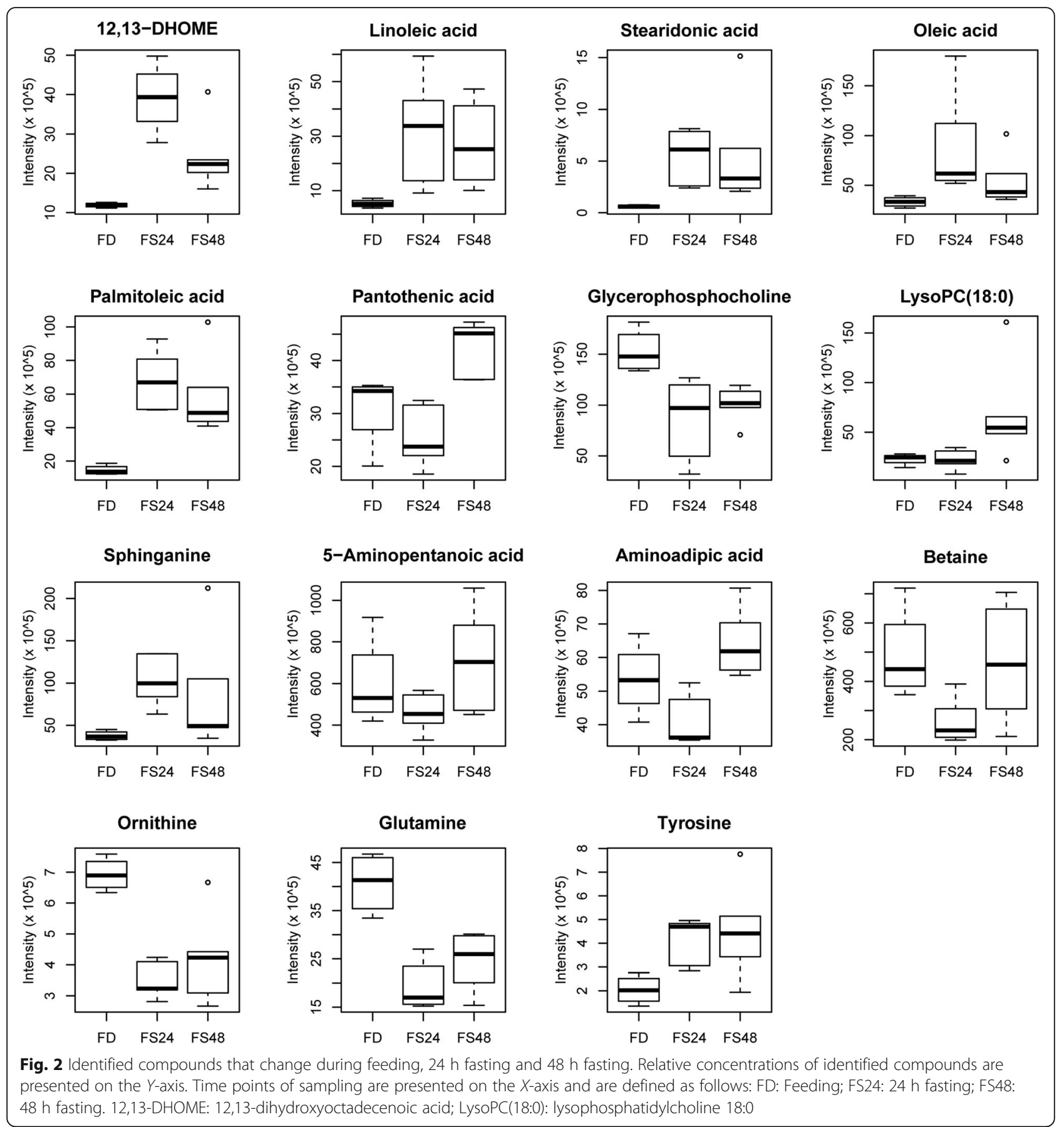

fasting, fatty acids are released from triacylglycerol stored in adipocytes of growing pigs, resulting in increased levels in plasma [47]. Wood et al. [48] concluded that more than half of the fatty acids in animal lipids were unsaturated fatty acids, and unsaturated fatty acids were oxidized more rapidly than saturated fatty acids $[49,50]$. The least oxidized of the saturated fatty acids having the greatest retention in the carcass [51]. In addition, multiple transcripts involved in the pathway of saturated fatty acids synthesis were inhibited in rat adipose tissue after short-term fasting [11]. Thus, the unsaturated fatty acids were more efficient energy substrate than saturated fatty acids, which may be explained that unsaturated fatty acids were primarily identified in the current study. Compared with the fed state, the fold change in the level of unsaturated fatty acids at $24 \mathrm{~h}$ and $48 \mathrm{~h}$ of fasting was close to 1 , which indicates that the level of unsaturated fatty acids level was not significantly different at $24 \mathrm{~h}$ and $48 \mathrm{~h}$ of fasting (Table 3). The pathway of linoleic acid metabolism was identified as the 


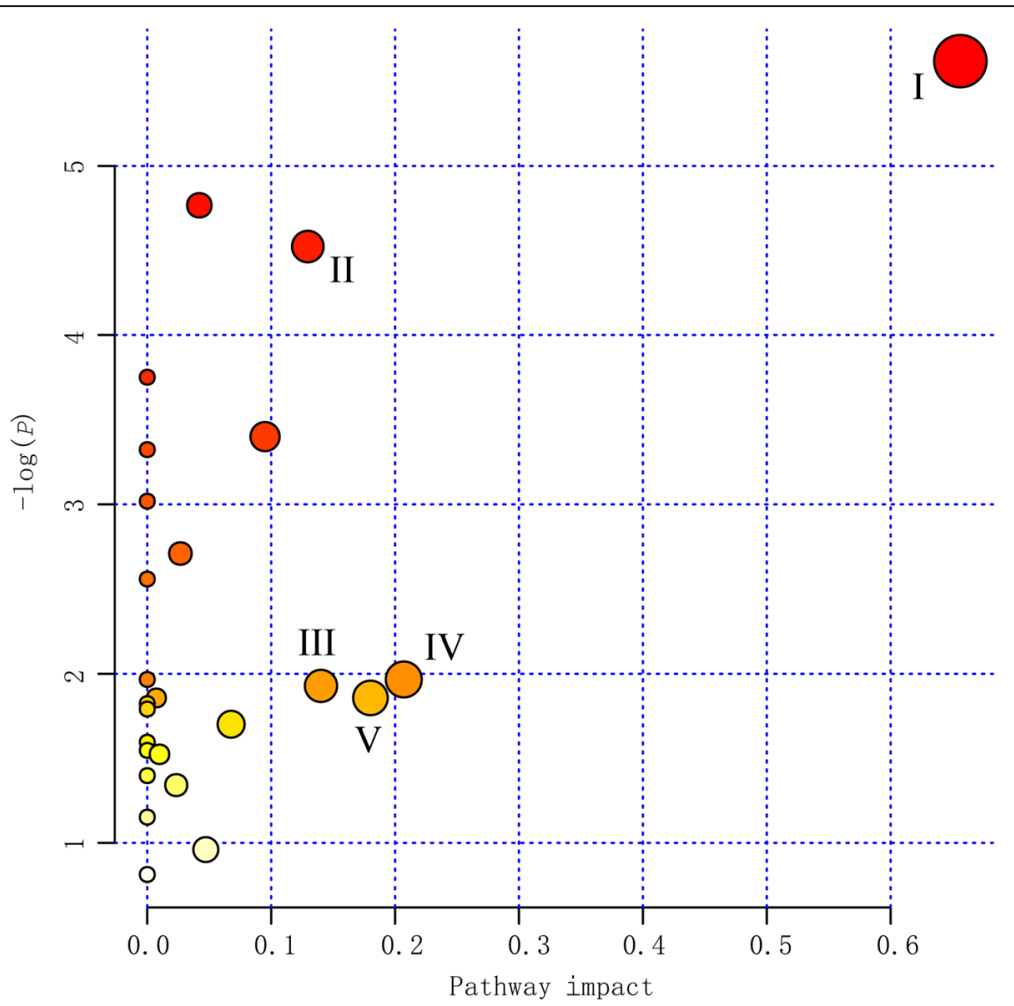

Fig. 3 Topology analysis of metabolic pathways identified among the feeding, $24 \mathrm{~h}$ fasting and $48 \mathrm{~h}$ fasting comparisons. The $X$-axis represents the pathway impact, and $Y$-axis represents the pathway enrichment. Larger sizes and darker colors represent greater pathway enrichment and higher pathway impact values, respectively. I: Linoleic acid metabolism; II: Arginine and proline metabolism; III: Sphingolipid metabolism; IV: Alanine, aspartate and glutamate metabolism; V: Pantothenate and CoA biosynthesis

most significant pathway through pathway topology analysis (Fig. 3). On the whole, the change of unsaturated fatty acid primarily contribute to fasting metabolism in our study and suggested that $24 \mathrm{~h}$ of fasting was more appropriate than $48 \mathrm{~h}$ of fasting for indicators of metabolic components of fasting metabolism.

In contrast, the GPC concentration was found to be significantly down-regulated during fasting. The GPC is a choline derivative that functions as a substrate in many bio-metabolic pathways [52]. As we know, the GPC is formed during the breakdown of phosphatidylcholine and is part of a phospholipid pathway that is active in many body tissues [53]. In the present study, fasting induced a significant decrease in the relative concentration of GPC, while the GPC level was not affected by the duration of fasting. Some studies have shown that the GPC level can be indicative for the ability to break down phospholipids as a fatty acid source to meet the energy requirements $[54,55]$. Low GPC values can be accompanied by a high level of ketone bodies, which are produced by the liver from fatty acids and serve as an energy source for tissues during starvation or prolonged exercise [56, 57]. A recent study by Klein et al. [55] suggested that GPC could be used as a prognostic method for the risk of ketosis. Therefore, a decline of GPC during fasting reflects a switch of energy metabolism from phospholipids to fatty acid oxidation when the available energy is limited [55]. In addition, the almost constant levels of GPC during 24 and $48 \mathrm{~h}$ of fasting indicates that phospholipids metabolism of growing pigs was relatively stable during fasting.

In addition to triglycerides, phospholipids and sphingolipids are also involved in lipid metabolism. Among the identified compounds of the current study, pantothenic acid and LysoPC (18:0) participated in phospholipid metabolism. Most of these metabolites showed a significant increase during the $48 \mathrm{~h}$ of fasting $[58,59]$. Pantothenic acid is an essential vitamin and required precursor for the biosynthesis of coenzyme A (CoA) in mammalian tissue [59]. Reibel et al. [60] reported that fasting resulted in higher tissue concentrations of Pantothenic acid, increased incorporation of Pantothenic acid into CoA, and elevated tissue concentrations of $\mathrm{CoA}$ in the liver. The CoA may act as an acyl group carrier in all living organisms, where it diverse cellular functions as an indispensable cofactor in energy metabolism, including the oxidation of fatty acids, carbohydrates, pyruvate, ketone bodies, and amino acids $[61,62]$. The increase of Pantothenic acid can be explained that the interconversion of Pantothenic acid and CoA in the tissue was accelerated in vivo by prolonged fasting to meet the energy requirement [63]. 
Interestingly, we found a significant decrease in the level of betaine at $24 \mathrm{~h}$ of fasting. Betaine has a main physiological function as a methyl donor in the (re)formation of methionine from homocysteine [64]. A recent study of Rubio-Aliaga et al. [6] showed that methionine levels declined over 50\% during fasting. The significant decline of betaine at $24 \mathrm{~h}$ fasting may be explained that betaine actively participates in the methionine cycle, which is a methyl donor taking part in several highly important methylation reactions [65]. However, the unexpected increase of betaine at $48 \mathrm{~h}$ of fasting may be explained by the observation that betaine can be maintained endogenously from choline, a process that occur mainly in the mitochondria of liver and kidney cells [66, 67].

Ornithine is a non-proteinogenic amino acid that plays an indispensable role in the urea cycle $[68,69]$. In the current study, fasting induced a significant decrease in the relative concentration of ornithine, whereas ornithine levels were not affected by prolonged fasting. The change in urinary nitrogen concentration coincided with the changes in ornithine level, which indicated that ornithine was intimately associated with urinary nitrogen excretion as an important intermediate of the urea cycle in mammals [70]. Similarly, glutamine concentrations were also decreased during fasting. Rubio-Aliaga et al. [6] reported that glutamine showed negative correlations with prototypical markers of fasting such as NEFA. Glutamine is an abundant amino acid in the plasma where it functions as a non-toxic nitrogen vehicle and a respiratory fuel [71]. The decline of glutamine may partly be explained by its role as a glucose precursor during fasting by providing carbon for gluconeogenesis $[16,72]$. The pathway topology analysis identified that ornithine and glutamine were enriched in the arginine and proline metabolic pathway. Recent studies reported by Pang et al. [69] indicated that proline catabolism was associated with lipid utilization by transcription factor SKN-1 during fasting. We speculated that there was a potential interaction between amino acid and lipid metabolism through those identified metabolites.

Tyrosine is not only a conditionally essential amino acid, but also a potent ketogenic amino acid [73]. Ketone bodies are formed in the liver and contributed as a fuel during fasting [74]. The level of tyrosine was significantly up-regulated during fasting in the current study. The increase of tyrosine may partly be explained by tyrosine acting as a ketogenic amino acid to meet the energy requirements of growing pigs during fasting $[75,76]$. In addition, compared with amino acids level in the fed state, the fold change of tyrosine, ornithine and glutamine level at $24 \mathrm{~h}$ and $48 \mathrm{~h}$ of fasting were close to 1 , which indicated that amino acids level were not significantly different at $24 \mathrm{~h}$ and $48 \mathrm{~h}$ of fasting.

\section{Conclusions}

In conclusion, a differential compound library containing 15 metabolites was identified that contributed to the differences in HP and RQ between the fed and the fasted state in growing pigs. Integrative analysis of indirect calorimetry and metabolomics profiling revealed that the decreases in $\mathrm{HP}$ and $\mathrm{RQ}$ of growing pigs under fasting conditions were associated with the alterations of linoleic acid metabolism and amino acid metabolism. The integrative analysis also indicated that growing pigs under a 24-h fasting were more appropriate than a 48 -h fasting to investigate the metabolic components of maintenance energy expenditure. Our findings help to improve knowledge regarding potential mechanisms responsible for metabolic components of maintenance energy expenditure and provide possible important implications for the design of effective strategies to study fasting mechanisms.

\section{Abbreviations}

ADF: Acid detergent fibre; DHOME: Dihydroxyoctadecenoic acid; DM: Dry matter; EE: Ether extract; GE: Gross energy; GPC: Glycerophosphocholine; HESI: Heated electrospray ionization; HP: Heat production;

LysoPC: Lysophosphatidylcholine; NDF: Neutral detergent fibre;

NEFA: Nonesterified fatty acid; PCA: Principal component analysis;

$\mathrm{RQ}$ : Respiratory quotient; UN: Nitrogen excretion in urine

\section{Acknowledgements}

The authors would like to thank $L$. Johnston for excellent assistance in editing the manuscript.

\section{Funding}

This study was financially supported by the National Natural Science Foundation of China (31372317), Developing Key Equipment for Digital Management and Monitoring Environment in Animal Production (2013AA10230602), Prevention and Control of Nutritional Metabolism and Toxic Diseases in Livestock and Poultry (2016YFD0501204) and the 111 Project (B16044).

Availability of data and materials

All the data were presented in the main manuscript and available to readers.

\section{Author's contributions}

$\mathrm{HL}$ carried out the animal trial, performed the statistics and drafted the manuscript. YFC, DXM, and JW participated in the experiments. ZL, XM, JJW, JVM and FLW critically evaluated the manuscript. All authors read and approved the final manuscript.

\section{Ethics approval}

All procedures used in this study were performed according to the guidelines for the ethical treatment of animal by the Institutional Animal Care and Use Committee of China Agricultural University (Beijing, China).

\section{Competing interests}

The authors declare that they have no competing interests.

\section{Author details}

${ }^{1}$ State Key Laboratory of Animal Nutrition, China Agricultural University, Beijing 100193, China. ${ }^{2}$ State Key Laboratory of Plant Physiology and Biochemistry, College of Biological Sciences, China Agricultural University, Beijing 100193, China. ${ }^{3}$ INRA, UMR Pegase, 35590 Saint-Gilles, France.

Received: 8 December 2017 Accepted: 19 April 2018

Published online: 16 May 2018

\section{References}

1. Noblet J, Fortune H, Shi XS, Dubois S. Prediction of net energy value of feeds for growing pigs. J Anim Sci. 1994;72:344-54. 
2. Milligan $L$, Summers $M$. The biological basis of maintenance and its relevance to assessing responses to nutrients. Proc Nutr Soc. 1986;45:185-93.

3. de Lange K, van Milgen J, Noblet J, Dubois S, Birkett S. Previous feeding level influences plateau heat production following a $24 \mathrm{~h}$ fast in growing pigs. Br J Nutr. 2006;95:1082-7.

4. Liu DW, Jaworski NW, Zhang GF, Li ZC, Li DF, Wang FL. Effect of experimental methodology on fasting heat production and the net energy content of corn and soybean meal fed to growing pigs. Arch Anim Nutr. 2014;68:281-95.

5. Noblet J, Labussière E, Dubois $S$, de Lange C, Barea R, Lasnier J, et al. Fasting heat production and metabolic body size in non-ruminant growing farm animals. Netherlands: Wageningen Academic Publisgers; 2013. p. 313-4.

6. Rubio-Aliaga I, de Roos B, Duthie SJ, Crosley LK, Mayer C, Horgan G, et al. Metabolomics of prolonged fasting in humans reveals new catabolic markers. Metabolomics. 2011;7:375-87

7. Li ZC, Li P, Liu DW, Li DF, Wang FL, Su YB, et al. Determination of the energy value of corn distillers dried grains with solubles containing different oil levels when fed to growing pigs. J Anim Physiol Anim Nutr. 2017;101:339-48.

8. Velayudhan D, Heo J, Nyachoti C. Net energy content of dry extruded-expelled soybean meal fed with or without enzyme supplementation to growing pigs as determined by indirect calorimetry. J Anim Sci. 2015;93:3402-9.

9. Inoue $H$, Watanuki $M$, Myint $H T$, Ito $T$, Kuwayama $H$, Hidari $H$. Effects of fasting and refeeding on plasma concentrations of leptin, ghrelin, insulin, growth hormone and metabolites in swine. Anim Sci J. 2005;76:367-74

10. Chelikani PK, Ambrose JD, Keisler DH, Kennelly JJ. Effect of short-term fasting on plasma concentrations of leptin and other hormones and metabolites in dairy cattle. Domest Anim Endocrinol. 2004;26:33-48.

11. Li RY, Zhang QH, Liu Z, Qiao J, Zhao SX, Shao L, et al. Effect of short-term and long-term fasting on transcriptional regulation of metabolic genes in rat tissues. Biochem Biophys Res Commun. 2006;344:562-70.

12. Schadewaldt P, Nowotny B, Straßburger K, Kotzka J, Roden M. Indirect calorimetry in humans: a postcalorimetric evaluation procedure for correction of metabolic monitor variability. Am J Clin Nutr. 2013;97:763-73.

13. Krueger R, Derno M, Goers S, Metzler-Zebeli BU, Nuernberg G, Martens K, et al. Higher body fatness in intrauterine growth retarded juvenile pigs is associated with lower fat and higher carbohydrate oxidation during ad libitum and restricted feeding. Eur J Nutr. 2013:53:583-97.

14. Moro T, Tinsley G, Bianco A, Marcolin G, Pacelli QF, Battaglia G, et al. Effects of eight weeks of time-restricted feeding (16/8) on basal metabolism, maximal strength, body composition, inflammation, and cardiovascular risk factors in resistance-trained males. J Transl Med. 2016;14:290.

15. Robertson DG, Ruepp SU, Stryker SA, Hnatyshyn SY, Shipkova PA, Aranibar $\mathrm{N}$, et al. Metabolomic and transcriptomic changes induced by overnight (16 h) fasting in male and female Sprague-Dawley rats. Chem Res Toxicol. 2011;24:481-7

16. Hedemann MS, Damgaard BM. Metabolomic study of plasma from female mink (Neovison vison) with low and high residual feed intake during restrictive and ad libitum feeding. Comp Biochem Physiol Part D Genomics Proteomics. 2012;7:322-7.

17. Dunn WB. Current trends and future requirements for the mass spectrometric investigation of microbial, mammalian and plant metabolomes. Phys Biol. 2008:5:011001.

18. Wishart DS. Metabolomics: applications to food science and nutrition research. Trends Food Sci Technol. 2008;19:482-93.

19. Lin G, Liu C, Feng C, Fan Z, Dai Z, Lai C, et al. Metabolomic analysis reveals differences in umbilical vein plasma metabolites between normal and growth-restricted fetal pigs during late gestation. J Nutr. 2012;142:990-8.

20. Bovo S, Mazzoni G, Calo DG, Galimberti G, Fanelli F, Mezzullo M, et al. Deconstructing the pig sex metabolome: targeted metabolomics in heavy pigs revealed sexual dimorphisms in plasma biomarkers and metabolic pathways. J Anim Sci. 2015;93:5681-93.

21. Zhang GF, Liu DW, Wang FL, Li DF. Estimation of the net energy requirements for maintenance in growing and finishing pigs. J Anim Sci. 2014;92:2987-95.

22. AOAC. Official methods of analysis. 18th ed. Arlington: Association of Official Chemists; 2007.

23. Thiex NJ, Anderson S, Gildemeister B. Crude fat, diethyl ether extraction, in feed, cereal grain, and forage (Randall/Soxtec/submersion method): collaborative study. J AOAC Int. 2003;86:888-98.

24. Van Soest PV, Robertson J, Lewis B. Methods for dietary fiber, neutral detergent fiber, and nonstarch polysaccharides in relation to animal nutrition. J Dairy Sci. 1991;74:3583-97.
25. Brouwer E. Report of sub-committee on constants and factors. Proceedings of the 3rd EAAP Symposium on Energy Metabolism; Troonn, Publ. 11. London: Academic; 1965. p. 441-3.

26. Simonson DC, DeFronzo RA. Indirect calorimetry: methodological and interpretative problems. Am J Physiol Endocrinol Metab. 1990;258:E399-412.

27. Chwalibog A, Thorbek G. Quantitative partition of protein, carbohydrate and fat pools in growing pigs. Arch Anim Nutr. 1995;48:53-61.

28. Le Bellego L, Van Milgen J, Dubois S, Noblet J. Energy utilization of lowprotein diets in growing pigs. J Anim Sci. 2001;79:1259-71.

29. Van Milgen J, Noblet J, Dubois S. Energetic efficiency of starch, protein and lipid utilization in growing pigs. J Nutr. 2001;131:1309-18.

30. Le Goff G, Dubois S, Van Milgen J, Noblet J. Influence of dietary fibre level on digestive and metabolic utilisation of energy in growing and finishing pigs. Anim Res. 2002;51:245-59.

31. Labussiere E, van Milgen J, de Lange CF, Noblet J. Maintenance energy requirements of growing pigs and calves are influenced by feeding level. Jutr. 2011;141:1855-61.

32. Widmaier EP, Raff H, Strang KT. Vander's human physiology: the mechanisms of human body function. New York: McGraw-Hill; 2006.

33. Chwalibog A, Tauson AH, Thorbek G. Energy metabolism and substrate oxidation in pigs during feeding, starvation and re-feeding. J Anim Physio Anim Nutr (Berl). 2004;88:101-12.

34. Ferrannini E. The theoretical bases of indirect calorimetry: a review. Metabolism. 1988;37:287-301.

35. Chwalibog A, Jakobsen K, Henckel S, Thorbek G. Estimation of quantitative oxidation and fat retention from carbohydrate, protein and fat in growing pigs. J Anim Physiol Anim Nutr (Berl). 1992;68:123-35.

36. Chwalibog A, Tauson AH, Thorbek G. Diurnal rhythm in heat production and oxidation of carbohydrate and fat in pigs during feeding, starvation and re-feeding. J Anim Physiol Anim Nutr. 2004;88:266-74.

37. Chwalibog A, Jakobsen K, Tauson A-H, Thorbek G. Energy metabolism and nutrient oxidation in young pigs and rats during feeding, starvation and re-feeding. Comp Biochem Physiol A Mol Integr Physiol. 2005;140:299-307.

38. Sinclair AJ, Murphy K, Li D. Marine lipids: overview" news insights and lipid composition of Lyprinol". Allerg Immunol (Paris). 2000;32:261-71.

39. Godsland IF. Biology: risk factor modification by OCs and HRT lipids and lipoproteins. Maturitas. 2004;47:299-303.

40. Lomb DJ, Laurent G, Haigis MC. Sirtuins regulate key aspects of lipid metabolism. Biochim Biophys Acta. 2010;1804:1652-7.

41. Taskinen MR, Nikkilä EA. Effects of caloric restriction on lipid metabolism in man changes of tissue lipoprotein lipase activities and of serum lipoproteins. Atherosclerosis. 1979;32:289-99.

42. Rodgers JT, Puigsenver P. Fasting-dependent glucose and lipid metabolic response through hepatic sirtuin 1. Proc Natl Acad Sci U S A. 2007;104:12861-6.

43. Zemel MB, Thompson W, Milstead A, Morris K, Campbell P. Calcium and dairy acceleration of weight and fat loss during energy restriction in obese adults. Obesity. 2004;12:582-90.

44. Nørskov NP, Hedemann MS, Lærke HN, Knudsen KEB. Multicompartmental nontargeted LC-MS metabolomics: explorative study on the metabolic responses of rye fiber versus refined wheat fiber intake in plasma and urine of hypercholesterolemic pigs. J Proteome Res. 2013;12:2818-32.

45. Nørskov NP, Hedemann MS, Theil PK, Knudsen KEB. Oxylipins discriminate between whole grain wheat and wheat aleurone intake: a metabolomics study on pig plasma. Metabolomics. 2013;9:464-79.

46. Miyazaki M, Kim YC, Ntambi JM. A lipogenic diet in mice with a disruption of the stearoyl-CoA desaturase 1 gene reveals a stringent requirement of endogenous monounsaturated fatty acids for triglyceride synthesis. J Lipid Res. 2001;42:1018-24.

47. Jensen MD, Ekberg K, Landau BR. Lipid metabolism during fasting. Am J Physiol Endocrinol Metab. 2001;281:E789-E93.

48. Wood J, Richardson R, Nute G, Fisher A, Campo M, Kasapidou E, et al. Effects of fatty acids on meat quality: a review. Meat Sci. 2004;66:21-32.

49. DeLany JP, Windhauser MM, Champagne CM, Bray GA. Differential oxidation of individual dietary fatty acids in humans. Am J Clin Nutr. 2000;72:905-11.

50. Jones PJH, Schoeller DA. Polyunsaturated-saturated ratio of diet fat influences energy substrate utilization in the human. Metabolism. 1988:37:145-51.

51. Leyton J, Drury PJ, Crawford MA. Differential oxidation of saturated and unsaturated fatty-acids invivo in the rat. Br J Nutr. 1987;57:383-93.

52. Loening NM, Chamberlin AM, Zepeda AG, Gonzalez RG, Cheng LL. Quantification of phosphocholine and glycerophosphocholine with 31P edited 1H NMR spectroscopy. NMR Biomed. 2005;18:413-20. 
53. Iorio E, Mezzanzanica D, Alberti P, Spadaro F, Ramoni C, D'Ascenzo S, et al. Alterations of choline phospholipid metabolism in ovarian tumor progression. Cancer Res. 2005;65:9369-76.

54. Fang F, He X, Deng H, Chen Q, Lu J, Spraul M, et al. Discrimination of metabolic profiles of pancreatic cancer from chronic pancreatitis by highresolution magic angle spinning $1 \mathrm{H}$ nuclear magnetic resonance and principal components analysis. Cancer Sci. 2007;98:1678-82.

55. Klein MS, Buttchereit N, Miemczyk SP, Immervoll AK, Louis C, Wiedemann S, et al. NMR metabolomic analysis of dairy cows reveals milk glycerophosphocholine to phosphocholine ratio as prognostic biomarker for risk of ketosis. J Proteome Res. 2011;11:1373-81.

56. Enjalbert F, Nicot M, Bayourthe C, Moncoulon R. Ketone bodies in milk and blood of dairy cows: relationship between concentrations and utilization for detection of subclinical ketosis. J Dairy Sci. 2001;84:583-9.

57. Newman JC, Verdin E. Ketone bodies as signaling metabolites. Trends Endocrinol Metab. 2014;25:42-52.

58. Elshorbagy AK, Nurk E, Gjesdal CG, Tell GS, Ueland PM, Nygard O, et al. Homocysteine, cysteine, and body composition in the Hordaland homocysteine study: does cysteine link amino acid and lipid metabolism? Am J Clin Nutr. 2008;88:738-46.

59. Smith CM, Song WO. Comparative nutrition of pantothenic acid. J Nutr Biochem. 1996;7:312-21.

60. Reibel DK, Wyse BW, Berkich DA, Palko WM, Neely JR. Effects of diabetes and fasting on pantothenic-acid metabolism in rats. Am J Phys. 1981;240:E597-601.

61. Tahiliani AG, Beinlich CJ. Pantothenic acid in health and disease. Vitam Horm. 1991:46:165-228.

62. Martinez DL, Tsuchiya Y, Gout I. Coenzyme a biosynthetic machinery in mammalian cells. Biochem Soc Trans. 2014;42:1112-7.

63. Smith CM, Narrow CM, Kendrick ZV, Steffen C. The effect of pantothenate deficiency in mice on their metabolic response to fast and exercise. Metabolism. 1987;36:115-21.

64. Lever M, Slow S. The clinical significance of betaine, an osmolyte with a key role in methyl group metabolism. Clin Biochem. 2010;43:732-44.

65. Tan Y, Ko J, Liu X, Lu C, Li J, Xiao C, et al. Serum metabolomics reveals betaine and phosphatidylcholine as potential biomarkers for the toxic responses of processed Aconitum carmichaelii Debx. Mol BioSyst. 2014;10:2305-16.

66. Pekkinen J, Olli K, Huotari A, Tiihonen K, Keski-Rahkonen P, Lehtonen M, et al. Betaine supplementation causes increase in carnitine metabolites in the muscle and liver of mice fed a high-fat diet as studied by nontargeted LCMS metabolomics approach. Mol Nutr Food Res. 2013;57:1959-68.

67. Craig SA. Betaine in human nutrition. Am J Clin Nutr. 2004:80:539-49.

68. Hallows WC, Yu W, Smith BC, Devires MK, Ellinger JJ, Someya S, et al. Sirt3 promotes the urea cycle and fatty acid oxidation during dietary restriction. Mol Cell. 2011:41:139-49.

69. Pang S, Lynn DA, Lo JY, Paek J, Curran SP. SKN-1 and Nrf2 couples proline catabolism with lipid metabolism during nutrient deprivation. Nat Commun 2014;5:5048

70. Weber AL, Miller SL. Reasons for the occurrence of the twenty coded protein amino acids. Mol Evol. 1981;17:273-84.

71. Aledo JC. Glutamine breakdown in rapidly dividing cells: waste or investment? BioEssays. 2004;26:778-85.

72. Hankard RG, Haymond MW, Darmaun D. Role of glutamine as a glucose precursor in fasting humans. Diabetes. 1997;46:1535-41.

73. Tanaka K, Ichihara A. Control of ketogenesis from amino-acids .3. Invitro and invivo studies on ketone-body formation, lipogenesis and oxidation of tyrosine by rats. Biochim Biophys Acta. 1975;399:302-12.

74. Balasse EO, Féry F. Ketone body production and disposal: effects of fasting, diabetes, and exercise. Diabetes Metab Res Rev. 1989;5:247-70.

75. Weinhouse S, Millington RH. Ketone body formation from tyrosine. J Bio Chem. 1949;181:645-53.

76. Meister A. Biochemistry of the amino acids. New York: Academic Press;1957.

77. NRC. Nutrient requirements of swine. 11th ed. Washington: Nat Acad Press; 2012.

\section{Ready to submit your research? Choose BMC and benefit from:}

- fast, convenient online submission

- thorough peer review by experienced researchers in your field

- rapid publication on acceptance

- support for research data, including large and complex data types

- gold Open Access which fosters wider collaboration and increased citations

- maximum visibility for your research: over $100 \mathrm{M}$ website views per year

At BMC, research is always in progress.

Learn more biomedcentral.com/submissions 